\title{
A Call for Change in the Public Education System in Nova Scotia
}

Barbara-Ann Hamilton-Hinch

Dalhousie University

Jessie-Lee D. McIsaac

Mount Saint Vincent University

Mary-Jane Harkins

Mount Saint Vincent University

Sherry Jarvis

Dalhousie University

John C. LeBlanc

Dalhousie University 


\begin{abstract}
The United Nation's International Decade for People of African Descent and Nova Scotia's Ministry of African Nova Scotian Affairs recognize that students of African descent continue to experience inequities. As previous studies indicate, parents of Black learners identified that many educators lack knowledge and experience in understanding students of African descent.This study explored student achievement from the perspective of parents of children of African descent attending public schools in Nova Scotia. Participants included individual interviews and focus groups with parents from rural and urban areas. Based on Bronfenbrenner's ecological theory framework, a thematic analysis of the data was conducted, a dominant storyline related to the families' experiences in school and subsequent themes emerged: we are treated differently; we don't feel connected; we know there are challenges: the resistance of parents; and we deal with injustices but persevere. These findings provide recommendations to improve the educational success for Black learners.
\end{abstract}

Keywords: African Canadian, academic achievement and success, Black students, education, schooling challenges, students of African descent

\title{
Résumé
}

La déclaration des Nations Unies de la Décennie internationale des personnes d'ascendance africaine et le Ministre des affaires Afro-néo-écossaises reconnaissent que les élèves d'ascendance africaine continuent à vivre des inégalités. Des études antérieures démontrent que les parents d'apprenants Noirs ont identifié que plusieurs éducateurs manquent de connaissances et d'expérience quant à la compréhension d'élèves d'ascendance africaine. Cette étude explore la réussite scolaire de la perspective des parents d'enfants d'ascendance africaine fréquentant des écoles publiques en Nouvelle-Écosse. Les participants incluent des entretiens individuels et des groupes de discussion avec des parents provenant de régions rurales et urbaines en Nouvelle-Écosse. Basée sur le cadre théorique écologique de Bronfenbrenner, une analyse thématique des données a été entreprise, un fil conducteur dominant lié aux expériences scolaires des familles, et des thèmes résolutoires ont émergé : nous sommes traités différemment; et nous ne nous sentons pas connectés ; nous sommes conscients qu'il y a des défis ; la résistance des parents ; et nous 
SPECIAL CAPSUlE ISSUE: AfRICAN EDUCATIONAL EXCELLENCE

font face à des injustices mais nous persistons. Ces constats fournissent des recommandations pour améliorer le succès académique des apprenants Noirs.

Mots-clés : Afro-canadiens, performance et succès académique, élèves noirs, éducation, défis scolaires, élèves d'ascendance Africaine 


\section{Introduction}

The response by the United Nations (UN) Human Rights Council to the United Nation's International Decade for People of African Descent stated that people of African descent represent a distinct group whose human rights must be promoted and protected (UN Human Rights Council, 2017). The Council (2017) identified the anti-Black structural racism found within the core of many Canadian institutions, which continues to have a negative impact on the human rights of African Canadians. To ensure the rights of African Canadians are promoted and protected, one must examine the long-term impact of enslavement, segregation, and marginalization on African Canadians. One institution that exposes African Canadians to anti-Black racism from a young age is the school system.

African Nova Scotian learners experience miseducation that can be identified by inequities such as low teacher expectations, stereotyping, and the absence of culturally relevant curriculum (African Nova Scotian Affairs, 2017; Hamilton-Hinch et al., 2017; Dei, 2008; Dei \& Calliste, 2000; Black Learners Advisory Committee, 1994; Smith et al., 2005; United Nations, 2014). The term African Nova Scotian is used to describe individuals who self-identify as descendants of Black Loyalists, Black Refugees, Maroons, and other original inhabitants of the 52 African Nova Scotian communities. The term African Canadian is used for individuals who are Canadian citizens and are not connected to one of the 52 African Nova Scotian communities (Hamilton-Hinch, 2016). This article examines parents' perspectives of their African Nova Scotian children's schooling experience, especially with respect to the "achievement gap" - the difference in academic achievement (as measured by standardized academic test scores) between African Nova Scotians and other Nova Scotian students (Lee \& Marshall, 2009; Frank, 2010; Thiessen, 2009) and actions of parents to positively influence the trajectory of their children. There is limited research on parents' perspectives, yet these perspectives have the potential to enhance our understanding of the how and why of the achievement gap and the important role of parents in the education of their children.

Learners of African descent indicate that they do not feel integrated in a meaningful way in the public education system (African Nova Scotian Affairs, 2017; Calliste, 1996; Halifax Regional School Board, 2003; Smith et al., 2005). Students often report that they feel their teachers neither sufficiently understand the African Nova Scotian culture nor have relevant training in Black history, race relations, and cross-cultural 
understanding (African Nova Scotian Affairs, 2017; Barnes \& Eadens, 2014; Barrett \& James, 2018; Calliste, 1996; Halifax Regional School Board, 2003; Hamilton-Hinch et al., 2017; Smith et al., 2005). As a result, most teachers cannot appreciate the difficulties and enormous challenges Black students face in the school system (Black Learners Advisory Committee, 1994; Halifax Regional School Board, 2003). The following section provides an overview of the literature on the identified achievement gap of Black students. It is important to note that the challenges African Nova Scotian students face are also experienced by Black students in other parts of Canada and other countries (Barnes \& Eadens, 2014; Carter, 2008; Codjoe, 2001, 2006, 2007; Smith et al., 2005; United Nations, 2014; Yull et al., 2014).

\section{Literature Review}

People of African descent have a long history in Nova Scotia, with large migrations starting in the 17th century (African Nova Scotian Affairs, 2019). Following the American Revolution, large numbers of Black Loyalists migrated to Nova Scotia (Pachai, 2007; Walker, 1992; Winks, 1997). They were followed by the exiled Jamaican Maroons. Black Refugees also sought freedom in Nova Scotia during the War of 1812 between the United States and Britain (Pachai, 2007; Walker, 1992; Winks, 1997). In the 20th century, immigrants from the Caribbean arrived in Nova Scotia to work in steel mills, coal mines, and homes as domestic workers (Calliste, 1989, 1993; Pachai, 2007).

African Nova Scotians have contributed to the culture of Nova Scotia, and have many achievements and triumphs in their 400-plus-year history. For example, the Jamaican Maroons helped build the Nova Scotia provincial legislature and the fortifications on the Halifax Citadel that overlook the harbour. African Nova Scotians have made substantial contributions to music, art, civil rights, and justice. Despite their contributions, however, African Nova Scotians have not benefited from the province's prosperity (African Nova Scotian Affairs, 2019; Bernard \& Bonner 2013; Etowa et al. 2017; Hamilton-Hinch et al., 2017; Hamilton-Hinch, 2016; McGibbon \& Etowa, 2009; Smith et al., 2005; Waldron, 2018) in large part because of systemic racism and discrimination in various structures such as judicial, governmental, economic, and educational systems (African Nova 
Scotian Affairs, 2019; James et al., 2010). It is within this context of generational racism and discrimination that Black students enter the educational system.

The challenges faced by African Nova Scotian students have been noted in other provinces in Canada and in the United States. Codjoe (2006) described the achievement gap of Black students as "one of the most troublesome and contentious issues in North American education" (p. 34). Codjoe (2001) reported that the "Public Enemy" of academic achievement for Black students must be addressed (i.e., racism and the negative impacts associated with it). Furthermore, students in the Canadian school-system experience racist name-calling, prevailing stereotyping, biases and/or exclusion from the school curriculum, low teacher expectations, and alienating school environments, which have resulted in isolation and loneliness (Hamilton-Hinch et al., 2017; Codjoe, 2007; Dei, 2008; James, 2012; Rummens \& Dei, 2010; Livingstone et al., 2014; Smith et al., 2005).

Research on Black students in the United States highlights similar struggles, including lack of cultural enrichment, feeling isolated (both parents and children), racism, cultural ignorance, lack of cultural competency in school systems and personnel, stereotyping of parents and children, disproportionality in Individual Program Plans (IPP), ${ }^{1}$ streaming of students in high school to non-academic courses, and suspensions and school discipline as a result of race (Carter, 2008; Cherng, 2016; Yull et al., 2014). Many of these challenges in part can be explained by "color blind" teachers (Ladson-Billings, 1994), which is a belief that obscures the inherent privilege of Whiteness, and inhibits the school's ability to recognize the impacts of racism-related stress through the daily exposure of racial micro- and macro-aggressions that racialized people experience (Ladson-Billings, 1994; Yull et al., 2014). Sue et al. (2009) have demonstrated that these microaggressions create a "clash of racial realities" (p. 335). This "places Blacks in an unenviable position of trying to ascertain the implicit meaning of such communications, whether incidents or comments were intentional or unintentional and then they face the quandary of formulating an appropriate response" (p. 335) in a society in which they lack power at both the individual and institutional levels.

1 IPPs are plans that are developed for students that have individualized learning outcomes; they can range from a single subject to the entire curriculum (Nova Scotia Department of Education and Early Childhood Development, 2016). 
Despite these many challenges, there are several attributes that promote academic success for Black students. While Carter (2008) acknowledged that Black students live in a culture that perceives them "as being academically disengaged and intellectually inferior by the larger society" (p. 12), her focus was on the counternarrative of Black school success. What enables Black students to persist in school despite the many challenges they face and maintain positive attitudes about schooling and academic performance? Findings from Carter indicate that having positive feelings about one's racial group (high racial centrality) and having a sense of connectedness to this group can provide protection for students in an unfriendly or isolating environment. Students were aware of the struggles of their ancestors and their ability to "beat the odds," and many found inspiration in seeing their ancestors overcome a history of oppression.

A supportive environment that reinforces knowledge and pride in Black cultural identity is a critical factor in success for Black students. A supportive environment was defined as one that is multi-ethnic in its approach, which "strive[s] to foster ethnic pride while at the same time facilitating mutual respect and cooperation" (Codjoe, 2006, p. 43) and values the differences that students bring to the classroom (Ladson-Billings, 1994). In addition, supportive and caring teachers, both Black and non-Black, who are committed to social justice education are instrumental in helping students succeed. They use teaching practices that encourage critical thinking, acknowledge social injustices and formulate counter-actions (Barnes \& Eadens, 2014; Carter, 2008; Codjoe, 2006; James, 2013). Teachers can foster a supportive environment by encouraging a critical race consciousness, creating a curriculum that encourages critical thinking, promoting culturally-relevant materials, and engaging parents (Carter, 2008; Dei, 2008; Delpit, 2006; Hamilton-Hinch et al., 2017; James, 2013; United Nations, 2014; Yull et al., 2014). Family support helps children develop self-confidence and self-esteem, and parental expectations regarding academic success is positively related to their child's school achievements (Cherng, 2016; Codjoe, 2006, 2007; Yull et al., 2014). Therefore, open and regular communication between family and school are key to promoting academic success.

The purpose of this study was to explore academic achievement among elementary school African Nova Scotian learners from the perspective of their parents, and lay the foundation for future research about the achievement gap and the important role of parents, as well as provide recommendations for educators and policy. By studying parents' perceptions and experiences, we gained a deeper understanding of the "what 
and how" of achievement challenges, including how to build on the positive experiences and their strengths. There is a paucity of research on the lived experience of African Nova Scotian learners in the public-school system, and therefore limited understanding of how current elementary school experiences influence childhood development among Black learners or their learning experiences later in life. The study used Bronfenbrenner's (1977, 1986) ecological framework to explore the perspective of parents of African Nova Scotian children's schooling experience and to assess the achievement gap in relation to developmental status at school entry and the important role of parents in the education of their children.

\section{Theoretical Framework}

The theoretical framework of this study is based on Bronfenbrenner's $(1977,1986)$ ecology of human development, which comprises nested circles of four inter-related systems (microsystem, mesosystem, exosystem, macrosystem) that have influence on the development of an individual (Bronfenbrenner, 1977) over time (chronosystem) (Bronfenbrenner, 1986). The dynamics between the child and the ecological contexts are examined from the child's immediate environment to broader societal contexts (Bronfenbrenner, 1977). The focus of Bronfenbrenner's ecological systems model is on identifying the changing processes of an individual's development as constructed through the interactions of the individual and the environmental influences over the life course. This approach allowed the researchers to explore not only the "what" and "how" of a topic but also the "why" (i.e., the reasoning behind the participant's contributions). This framework provides a broad overview of the complexity of different influences that can have an impact on a child's schooling experiences.

\section{Methodology}

The Qualitative Description method was used because it is appropriate to provide a thorough account of participants' experiences (Neergaard, et al., 2009; Sandelowski, 2000). It also allows first voice accounts of participants' interpretations of their lived experiences and attempts to represent these experiences to be as close as possible to their own 
accounts of these experiences (Wiersma \& Jurs, 2009). As qualitative description is less interpretative than other qualitative methodologies (Neergaard et al., 2009; Sandelowski, 2000 ), the researchers identified key themes directly from participants' experiences (as recounted during focus groups and interviews) and used these to directly inform recommendations for educators and other professions working with African Nova Scotian learners. The team of researchers consisted of a principal investigator who self-identifies as an African Nova Scotian woman, two women of European descent, one woman of European descent with two children who self-identify as African Canadian, and one male of European descent. Ethical approval was provided by the Dalhousie University and Mount Saint Vincent University Research Ethics Boards.

\section{Recruitment}

Potential participants were recruited with help of Regional Educators from the Nova Scotia Black Educators Association and members of the African Nova Scotian community, who helped distribute recruitment posters and contact community organizations across four regions in Nova Scotia. Purposive snowball sampling (Palinkas et al., 2015) was employed to recruit parents of children of African descent in Grades 4 and 5 who had attended public school in Nova Scotia from Grade Primary to Grade 5. Every effort was made to recruit participants from both urban and rural regions. Interested parents were asked to contact the principal investigator, or the research assistant, to ensure participants met these criteria: African Nova Scotian or non-African Nova Scotian parents (some were White) of children of African descent who were in Grade 4 or 5 in a Nova Scotia school. Participants needed to be able to understand and speak English. Participants engaged in a single 90-minute focus group session, and in addition 12 of them participated in individual interviews of up to one hour. The focus group meetings took place in participants' communities at a time convenient to all, in an agreed-upon and readily accessible public location. Participants were provided with an honorarium for their participation in the study.

\section{Data Collection}

Four focus groups (three groups of four participants and one group of five) and 12 individual interviews were conducted in communities across Nova Scotia with a total of 29 
participants. Open-ended guiding questions were developed by the researchers and used during the focus groups and individual interviews (Morgan, 1996, 1997) to gain insight into how race may have played a role in the school experiences of participants and their children. Participants were also asked about their perceptions of any notable challenges within the school system, the impact of these challenges, and what factors might have contributed to them. With permission from participants, the focus group and interviews were recorded so that participants' experiences could be transcribed verbatim.

\section{Data Analysis}

During transcription of the focus groups audio recordings, all identifying information of the participants was removed, and the transcripts were imported into a qualitative data analysis software (QSR NVivo Version 12) to organize and code the data. Using labels taken from the words of participants, four research team members independently reviewed selected transcripts and used inductive coding strategies to identify and define emerging codes (Reinharz, 1992; Ristock \& Pennell, 1996). Team members reviewed the transcripts independently, then met as a team to discuss codes and themes. Differences were discussed until agreement about the codes and definitions was reached. Inter-rater reliability methods were used to ensure consistency across the coding of the interview transcripts (Neuman \& Robson, 2007). After the data were coded inductively, theoretical coding was conducted to explore ideas and insights emerging through data analysis that included identifying patterns, similarities, and repetitive and shared experiences. These were then organized into agreed-upon themes (Miles \& Huberman, 1994).

\section{Findings}

Participants were 29 parents of children of African descent from three rural communities and one urban community. Parents were asked about their schooling experience as well as that of their children. In cases where the parents' experiences and their perspectives of their children's schooling experiences were similar, we used the collective word "they." If the experiences differed, we indicated if it was the parents' or child's experience being 
referenced. Pseudonyms ${ }^{2}$ were used to ensure anonymity of the participants. Four themes, centred on a dominant story of "Our Families' Experiences in School” were identified: (1) "We are treated differently," (2) "We don't feel connected," (3) "We know there are challenges: The resistance of parents," and (4) "We deal with injustices but we persevere."

\section{Our Families' Experiences in School}

Overall, most participants, who are now parents, said they liked school in spite of challenges. For example, one participant stated their children also enjoy school:

All three of my children, they enjoy school and they look forward to going, so that's half the battle, I don't really have to fight with them too much to get them to go to school, and overall they're happy with their teachers. (Karen)

Several participants, in recalling their own schooling experiences, stated that (in addition to liking teachers, socializing with friends, and being motivated to learn) extracurricular activities in school and after school were important to their enjoyment of school. These activities included intramural sports, informal sports, drama clubs, and choir. One participant even discussed how singing helped her deal with stresses that she experienced in school:

Just singing, I used to like it when the variety shows and stuff would come up, boom that was my time because then...it was all eyes on me, that was the only time that I could make my position within my peers right but like I said with my teachers I couldn't create that same effect. (Ann)

However, several participants reported that their own negative experience in school resulted in unpleasant memories and a dislike for school:

Well it was a roller coaster ride for me. In elementary I liked going to school then around junior high I didn't like it so much and then when I got to high school I started to like it again...I think football helped, I think that's what it was, more so than anything that had to do with the curriculum. (Jay)

2 To honour teachers of African descent in the Nova Scotia public school system, pseudonyms are represented by some of their names. It's important to note that none of these teachers participated in the research. 
Regardless of the level of enjoyment in school, all participants discussed the challenges they experienced in the Nova Scotia school system, as many felt they were treated differently. They also recognized the role they now have to play as parents to ensure their children receive equitable education.

\section{We Are Treated Differently}

The majority of participants commented on how they were treated differently in school as a consequence of racism, resulting in negative school experiences, but also on how the support from parents and community made a difference for them: "I hated [school] and in fact I hated it because we got treated differently" (Malik). Participants in all focus groups acknowledged that they experienced both implicit and explicit racism during their education, which included negative comments, being falsely accused, being ignored or excluded, and being more harshly judged or punished than other students.

Several participants discussed not feeling comfortable or welcomed at school and that they felt excluded to "segregated spaces," as well as feeling like a "sore thumb." Many felt that they did not belong in certain spaces or programs, which caused them undue anxiety and feelings of exclusion and loneliness:

One of the main issues that is going on with Black children in the school, it doesn't matter what age you are, [it's] that comfort, that welcoming feeling that you can participate and you know that you're not different than anybody else. That anxiety is always there if you're really actually welcomed in the space or if you're included...well I had challenges like just simply feeling like a sore thumb...I didn't feel like I belonged. (Karen)

Some parents reflected on their own experiences as a student and identified comfort in spaces when teachers or administrators were also Black. As one participant stated, "That was the reason that I wanted to go to school so that I could be in the classroom with my Black teacher" (Ann). Similarly, Darcel reflected on her experiences with Black administrators and teachers when she attended a school in her community and being bussed to attend secondary level school in a non-Black community, explaining that the importance of seeing herself represented in Black teachers made a difference: 
You had the Black principal, the Black vice-principal, and all these Black teachers

and cause that's what you were used to so it was kind of like a culture shock going outside of the community but we grew up going to school in the community, everybody knew everybody so it was very connected and it was very nice. (Darcel)

Many participants acknowledged that they had positive experiences with White teachers as well — one recalled a White teacher telling him to "go back in the classroom, show them what you are capable of, show them that you can do it" (Jay) — but representation or seeing yourself is certainly an important component for a positive learning environment in all aspects of schooling such as teachers, curriculum, programs, and resources.

Parents did their best to stay involved in their children's education, to ensure they were being treated fairly so that the cycle of generational trauma did not continue:

You know their marks went down a bit in Grade 7 but quickly rose back up, but that's because I was a strict parent, and I was a single parent and they were not going to fail so I was at everything, sports and everything, and if we do that every teacher in the school will have to work with us. (Darcel)

Several participants noted that racism has changed over time, in different ways, but it still continued. They stressed the importance of staying actively involved in all aspects of their children's education.

\section{We Don't Feel Connected}

Many participants stated that they were not given enough information about their child(ren)'s education. They felt they were not informed right away when problems arose and did not receive information in a timely manner. In many cases, they learned about problems at parent-teacher interviews. Several talked about the importance of engaging with teachers/developing relationships with them so that challenges could be dealt with promptly: "If the parent isn't involved you don't know until it's too late" (Shyanne). Lack of communication was particularly concerning for Individualized Program Plans (IPPs); participants discussed how an IPP was not explained properly to them, or that they were given wrong information. More problematic is that some children were enrolled in IPPs without parents knowing or giving their consent: 
When they're on the IPP program a lot of people don't know, your chances of going to university [are] very slim. And they don't tell you. And a lot of parents don't know that. I mean they can get into probably certain things, community college or something... And they don't tell them that. No, they set our Black kids up for failure. (Venessa)

Feeling disconnected from the school community or a lack of a sense of belonging can result in some parents not being able to advocate for their children because they do not know how the system works or how to challenge it.

Additionally, participants had to deal with the assumptions that some teachers made about them. For example, it was assumed that they were not employed and therefore were readily available to collect their child if there were issues. One parent of a child with disabilities stated:

I found it difficult and this is just my personal opinion being an inner-city school. I don't know why they assume that I'm home in the middle of the day, that aggravates me, I work Monday to Friday, 9 to 5. Text me, email me, I'm at my desk I can respond. I cannot take off at 10 o'clock in the morning to come pick up my child. I don't understand why you can't wrap your head around it but it was assumed so I felt offended, 'cause it was assumed that I was just at home and I could just come, and I wasn't. (Wendie-Lee)

The assumptions that teachers and school administrators had about Black parents resulted in miscommunication and caused many parents to feel frustrated and misunderstood. Wendie-Lee felt the school only saw her as a "stay at home mom," rather than someone who is employed out of the home, with little flexibility during the work day. It is noteworthy that many participants acknowledged they would like to have a positive relationship with their child's teachers and better engagement with them. Some would attend all events, including parent-teacher meetings, and they would be asked why they were there, as stated by one participant:

I'd go to parent/teacher meetings they'd ask me why did I come? I come because my daughter is here. Well no you don't need to come, it's the ones that aren't doing well that we want to see, and I said it does not matter, I will be at every one and sitting there and in line for every teacher, every school year. (Darcel) 
It was important for Darcel to disrupt the narrative of Black parent disengagement and other stereotypes often associated with Black parents. Parents felt that families and communities played an important role in the education of their child. For many of the participants, their communities provided a strong sense of family and helped children deal with feelings of not being connected.

So there was so much love within the community, within my family, I have nine sisters, two brothers so I think, they kind of like impacted all that's positive because living in [location] there's, this is the colour you get...it's very easy when you're out there that you know that everybody's got your back, so it's very easy when you walk into a room or a classroom. (Darcel)

Historically, Black communities have played a pivotal role in the educational growth of Black children by giving them a place to feel connected, despite their experience in the school system. This sense of connectivity provided a shield of resistance and strength to deal with the injustices.

\section{We Know There Are Challenges: The Resistance of Parents}

Participants noted that not only was the distribution of school resources not equitable, even the types and quantity of resources that were available for Black students, when compared to others, were not equitable either. For example, one parent discussed how an after-school event to celebrate Black History Month was cancelled so that a book fair could take place. The parent believed the book fair could have taken place at any time, unlike the Black History Month event. As well, culturally-relevant resources such as books, movies, and posters were not available in many schools:

And another thing that I notice too it's so hard for our children to have an after-school program because we have to use the resources that are provided by the school, which is majority White, and it seems like whenever we need the time or the space for something, oh they need it for something else. (Karen)

Beyond unequal distribution of physical resources such as books or space, there are fewer opportunities for academic success for Black students. Several participants 
reported that their children were "streamed" into less academically challenging courses, or were not encouraged to enroll in advanced courses:

When I went to the last parent and teacher [meeting] like he did stellar Grade 9 right? When I went to parent and teacher, the teacher recommended that I put him in...what's the dummy math?... So I said to the teacher why do you suggest that? And she said because of the workload. So I looked at it, I said because of the workload? She said yah he'll bring home homework every day, I said well isn't it school? Aren't they to bring homework home? And I said to her, I don't know. So I put [name] in his academic math, no you're not going to make him feel that he's not capable. (Venessa)

Based on personal experiences, and to protect their children, parents became powerful advocates. In some cases, this was due to the parent's experience of being treated differently (lower expectations) and they did not want that to be their child's experience: "That's my goal, is to stay connected with the teachers and also get the feedback from my children, make sure that they're happy and that they're thriving and achieving and so, that's a job in itself" (Francis). Parents had to be advocates for their children to fight against generational streaming. Parents wanted to make sure that all options to further their children's education were available and not limited based on perceived challenges.

Another challenge identified by participants is that the curriculum did not reflect their culture or ways of knowing or learning. One participant mentioned that their child, who is on an IPP, was able to learn math at an Africentric camp, but struggled in the school classroom:

When she goes to the summer camp for our African Nova Scotian kids...she's doing math that they don't even do in Grade 5 but when she goes back to school, it's like she doesn't know how to add any more, she doesn't know how to do simple multiplication, but when she goes to that camp, she's doing fractions... and decimals and [difficult] math. (Karen)

Some parents knew the importance of an Africentric education to instill in their children a sense of pride and confidence, and as a strategy enrolled them in Africentric programs. This experience was highlighted by other participants. Moreover, the lack of culturally 
relevant resources/curriculum reinforced feelings of "not belonging" as previously discussed. One parent advocated for the implementation of an Africentric curriculum:

I think our children from Grade Primary should have African-centred curriculum that they can look in the book and see themselves and you don't have to wait until you get to high school to take African Canadian Studies. They should be learning this from elementary, all students. (Darcel)

Parents stated providing African-centred resources, spaces, and curriculum could positively contribute to the students' academic success and connection to learning. One participant noted how pleased they were to see diversity: "[Name of school] is a really good school for diversity...I went up the other day and they had like African masks in the foyer and posters all over the walls" (Angela). Reflecting on their own educational experience, parents recognized and knew the importance of advocacy and resistance to improve the education of their children, but faced so many challenges to do so.

\section{We Deal with Injustices but Persevere}

To deal with the many challenges faced in schools, participants discussed several ways that they cope with them. Many participants highlighted how they are actively involved with their children's education by consistently engaging and communicating with teachers, helping children with their homework, and attending parent and teacher interviews so that their children's needs were being met. Many participants thought that teachers and parents needed to communicate more. One participant stated that

There just needs to be more communication [between parents and teachers], you just shouldn't be able to chuck somebody on IPP and not talk with a parent, you shouldn't be able to give somebody half a day off and not talk to the parent. (Alicia)

Many participants discussed how they had to "fight" and advocate for their children to ensure that they received the supports and resources their children needed:

So I didn't have a good experience but I will not allow that to harm my kids.

Like I make sure that they have exactly what they need because I know what the 
system did to me. For me it was awful, I feel they failed...but I don't allow them to do that to my kids because I'm on it all the time. (Rosalie)

Another participant recalled, "I was told this by my mother that they wanted to hold me back when I was in Grade...1...they said [I was] like slow or something... and I wasn't... and my mother argued with them...but they didn't" (Doreen). Doreen's mother advocated on her behalf to ensure that every opportunity was made available to her for academic success. This provided a role model for her, to continue to advocate for her own child. Finally, many participants highlighted the importance of keeping teachers accountable to their responsibilities as teachers: "The teachers have to make time for students and get to know what a student [is capable of], that's what they're paid to do, to get to know what a student can do or what they can't do" (Francis). Parents tried to apply the intergenerational transfer of strategies of resistance and advocacy in parenting their children in a system that seemed to fight against them.

Parents critically evaluated many positive attributes of the school system, but they also noted ways in which it could be improved to better meet the needs of their children. Their previous experiences in the school system (positive and negative) made them more aware of their children's needs and the importance of working collaboratively with the school system.

And the thing that gets me, especially in this community where most, you guys have gone to daycare, but you come out of daycare and you go to [name of school] and everybody in that school is all the same. Their marks are all the same, and then as school starts, somewhere along the line ours [Black children] go down. So what happens? (Darcel)

Asking more questions like "So what happens?" can work to improve the academic success of Black children.

\section{Discussion}

This study provides valuable insight into the lived experiences of parents and their children of African descent in the Nova Scotia public school system and provides important understandings that can be used to inform other school systems. Their experiences reflect 
the importance of positive communication and relationships among school, home, and community, consistent with the Bronfenbrenner $(1977,1986)$ ecological framework. If there were more Black teachers and culturally-relevant curricula that reflected students of African descent, they would likely develop a stronger sense of self and see school as a place where they belong and can excel (James, 2013; Rummens \& Dei, 2010). Many Black students reported not feeling connected to their schools and did not feel that they belonged. The implications of the findings of this study suggest a need for in-servicing and professional development for teachers of all ethnic and racial backgrounds to become aware of the parents' perspective of the systemic inequities and hidden racism in the present educational system, and to learn culturally relevant strategies that will improve the education for Black children (Cherng, 2016; Delpit, 2006; James, 2013; United Nations, 2014; Rummens \& Dei, 2010). In addition, there is a need to increase the number of Black teachers, administrators, and guidance counsellors. Building on the suggestions from Codjoe (2001) and Barrett and James (2018), schools, teachers, and school administrators need to recognize the racism and inequities that exist and work collaboratively with the community and parents to improve it. Indeed, building a relationship with parents and engaging them as partners is a key action that school staff can implement to create a safe environment where children can thrive and be academically successful (Barrett \& James, 2018; Carter, 2008; Codjoe, 2007; Cherng, 2016; Yull et al., 2014). Participants in this study expressed a desire to have an engaging relationship with their children's schools and to be included in any decisions regarding their education. Most importantly, any course of action must be discussed and approved with the parents before students are placed on a modified education plan.

Bronfenbrenner $(1977,1986)$ identifies the impact of the macro system on individual lives. The participants also acknowledged that there are societal challenges in the education system that lead to negative consequences. At the same time, there was recognition of the importance of and need for a quality education for advancement. This finding has been previously reported by Smith et al. (2005), who found that Black students were aware of these expectations and aspired to achieve academic success, but this effort was not always reflected in their levels of academic achievement. This could be attributed to factors identified by the research participants and reflected in the academic literature such as low expectations by teachers, and curriculum that does not mirror or 
include them (Codjoe, 2006; Dei, 2008; Rummens \& Dei, 2010; United Nations, 2014; Yull et al., 2014).

One strategy to better engage Black communities in education is for all educators to gain an awareness of, and respect for, the local knowledge of the community, and to provide culturally relevant pedagogy and culturally sensitive curriculum and classroom resources. For example, there is an identified lack of African Canadian material in schools (Hamilton-Hinch et al., 2017; Finlayson, 2015; United Nations Human Rights Council, 2017), thereby ignoring the contributions that African Canadians, and specifically African Nova Scotians, have made to the Canadian culture. While celebrating African Heritage month highlights the important contributions of Black people, these contributions should be incorporated throughout the regular curriculum, and not just highlighted during particular time periods. Moreover, school resources such as posters, books, and worksheets should represent the diversity of Nova Scotia classrooms. Being recognized is something that students of European descent take for granted, but most African Nova Scotian students feel invisible and not represented in school life. To promote academic success, the curriculum must reflect the daily realities and experiences of all students (Brathwaite, 2010). Implications for higher education, particularly teacher education, suggest that programs need to explore ways of educating and diversifying current faculty, staff, and students. There is a need for pre-service teachers to develop strategies to connect with their students in ways that create positive, trusting relationships. Previous research has discussed the importance of exploring the ways in which culturally sensitive pedagogies can be incorporated into all facets of pre-service and in-service teacher education (Cherng, 2016; Hamilton-Hinch et al., 2017; James, 2013; Rummens \& Dei, 2010).

Providing ample opportunities for extracurricular activities for Black students emerged as an important finding in this research. Extracurricular activities provided a protective feature for some participants that helped them deal with the many challenges they faced. The benefits of extracurricular activity include "higher levels of emotional well-being, motivation, and academic and social success" (Logan \& Scarborough, 2008, p. 157). Participating in extracurricular activities that facilitate supporting and caring relationships with teachers and other staff provides an avenue to explore new experiences, learn new skills, and build appropriate coping mechanisms. These extracurricular activities form a part of the mesosystem for the child, and connections (over time) between the 
mesosystem and microsystem (the classroom) can support the child's positive development (Bronfenbrenner, 1977, 1986).

Teachers and school administrators need to be more aware of the systemic power structures within the exo and macro system (Bronfenbrenner, 1977, 1986) that privilege certain voices as well as the implications of their actions (conscious or unconscious) on Black students, such as low expectations, streaming them into non-academic courses, and placing them on IPPs before alternatives are explored. James (2013) encourages teachers to take a social justice and equity approach to teaching in which they get to know their students (and students' parents), build relationships with them, and allow them to share their life experiences (i.e., to have their voices heard). This approach gives students an opportunity to express their identities in positive and safe environments, which fosters a sense of belonging, inclusion, and visibility (Rummens \& Dei, 2010). A social justice and equity approach to teaching requires teachers to think critically about their own discriminatory thoughts and practices and to reject a colour-blind approach that ignores the differences that children bring to the classroom (Carter, 2008; Yull et al., 2014). A colour-blind approach impedes meaningful engagement with Black people, hides the privileging of the White experience in curriculum and representation, and ignores the impact of structural racism experienced by many students in the Canadian education system (Burke, 2017).

In the face of these challenges, many participants discussed the importance of resisting systemic, structural, and institutional racism and advocating for their children within the school system to increase the opportunity for better learning outcomes. Participants' experiences highlighted the recurring challenges that Black students face in the school system and how those challenges contribute to the ongoing struggle for higher education, employment, and socio-economic status. Participants also discussed the important role of parents and community in the success of their children. The findings in this study identify specific actions that relate to Bronfenbrenner's $(1977,1986)$ ecological framework and demonstrate the importance of addressing these academic challenges. Following the analysis of the participants' voices and experiences, we recommend:

1) Implementing effective communication with a posture of listening with every parent (particularly racialized parents) so that they feel welcomed and included in the school (Micro). 
2) Increasing representation of Black educational staff (including teachers, administrators, counsellors, resource teachers, and student support workers) in the school system (Micro/Meso).

3) Creating professional opportunities to support education staff in recognizing implicit bias and racism in themselves and those around them (Micro/Meso).

4) Circulating information for educators and policy developers discussing how their actions (conscious or unconscious), such as low expectations, withholding of resources, and adaptations to programs made without sufficient consultation with parents, can have consequences for racialized students and their parents (Exo/Macro).

5) Encouraging interaction between educators and local community members with whom they are working to better appreciate culture and the historical trauma experienced by some community members (Exo/Macro).

Implementation of these recommendations could help to address the issues identified by parents and lead to improved academic success of Black learners.

\section{Conclusion}

This study adds value to the emerging issue of the challenges experienced by Black students, and suggests ways to address them. By documenting the first voice experiences of parents and their perception of their children's experiences, we gain a better understanding of the challenges experienced by students of African descent in the Nova Scotia public school system, the role of parents and community, and the potential protective factors that can be implemented to address the achievement gap. A limitation of this study concerns recruitment. As it was difficult to recruit from regional populations that have experienced racism and have therefore developed mistrust of many institutions, a purposeful snowball sampling approach was used to recruit participants. Selection bias may have translated to some participants who were more likely to be interested in the study, had more time to participate, and felt comfortable talking frankly in a group setting.

According to a report published by the Black Learners Advisory Committee (1994), as cited by the UN Human Rights Council (2017), "The education inequities between African Nova Scotians and other Nova Scotians have remained unchanged after 
30 years of school integration" (p. 12). It is imperative that the challenges experienced by Black students be addressed and the attributes that promote success be strengthened, as outlined in our recommendations. From a research perspective, researchers working with racialized communities should establish partnerships with community organizations to help with the recruitment of participants. This was a strength of this research, as community partners who have established relationships with the parents helped with the recruitment of parents from urban and rural communities. The first-voice experiences of the parents reinforce the need for an educational context that recognizes, values, and creates a sense of belonging. Culturally responsive school environments with genuine engagement with parents as educational partners, can stop the intergenerational trauma and enhance schooling success for students of African descent. 


\section{References}

African Nova Scotia Affairs. (2017). Count us in: Nova Scotia's action plan in response to the International Decade for People of African Descent. Government of Nova Scotia.

African Nova Scotian Affairs. (2019). African Nova Scotian community: A look back. Government of Nova Scotia. https://ansa.novascotia.ca/community

Barnes, J. A., \& Eadens, D. (2014). A study into the perceptions of students of color and their ninth-grade academic experience. Education Leadership Review of Doctoral Research, 1(1), 25-38.

Barrett, S. E., \& James, C. E. (2018). Teacher stories of teaching for social justice in a marginalized community. In S. Singer \& M. J. Harkins (Eds.), Educators on diversity, social justice, and schooling: A reader (pp. 178-193). Canadian Scholars Press.

Bernard, W., \& Bonner, C. (2013). Kinship and community care in African Nova Scotian communities. Journal of the Motherhood Initiative, 4(1), 155-167.

Black Learners Advisory Committee (BLAC). (1994). BLAC report on education: Redressing inequity - empowering black learners (Vols. 1-3). Black Learners Advisory Committee.

Brathwaite, O. (2010). The role of the school curriculum to obliterate anti-black racism. Our Schools/Our Selves, 19(3), 305-326.

Bronfenbrenner, U. (1977). Toward an experimental ecology of human development. American Psychologist, 32(7), 513.

Bronfenbrenner, U. (1986). Ecology of the family as a context for human development: Research perspectives. Developmental Psychology, 22(6), 723.

Burke, M. (2017). Colorblind racism: Identities, ideologies, and shifting subjectivities. Sociological Perspectives, 60(5), 857-865.

Calliste, A. (1989). Canada's immigration policy and domestics from the Caribbean: The second domestic scheme. Race, Class, Gender: Bonds and Barriers, 5, 133-165. 
Calliste, A. (1993). Race, gender and Canadian immigration policy: Blacks from the Caribbean, 1900-1932. Journal of Canadian Studies, 28(4), 131-148.

Calliste, A. (1996). African Canadians' organizing for educational change. In K. S. Brathwaite \& C. E. James (Eds.), Educating African Canadians (pp. 87-106). James Lorimer \& Company.

Carter, D. J. (2008, Winter-Spring). Cultivating a critical race consciousness for African American school success. Educational Foundations, 11-28.

Cherng, H. (2016). Is all classroom conduct equal?: Teacher contact with parents of racial/ethnic minority and immigrant adolescents. Teachers College Record, $118(11), 1-32$.

Codjoe, H. (2001). Fighting a 'public enemy' of Black academic achievement - the persistence of racism and the schooling experiences of Black students in Canada. Race, Ethnicity and Education, 4(4), 343-375.

Codjoe, H. (2006). The role of an affirmed black cultural identity and heritage in the academic achievement of African-Canadian students. Intercultural Education, $17(1), 33-54$.

Codjoe, H. (2007). The importance of home environment and parental encouragement in the academic achievement of African-Canadian youth. Canadian Journal of Education, 30(1), 137-156.

Dei, G. J. S. (1996). Listening to voices: Developing a pedagogy of change from the narratives of African-Canadian students and parents. In K. S. Brathwaite \& C. E. James (Eds.), Educating African Canadians (pp. 32-57). James Lorimer \& Company.

Dei, G. J. S. (2008). School as community: Race, schooling, and the education of African youth. Journal of Black Studies, 38(3), 346-366.

Dei, G. J. S., \& Calliste, A. (2000). Power, knowledge and anti-racism education: A critical reader. Fernwood Publishing.

Delpit, L. (2006). Lessons from teachers. Journal of Teacher Education, 57(3), 220-231.

Etowa, J., Beagan, B., Eghan, F., \& Thomas Bernard, W. (2017). Your feel like you have to be made of steel. The strong Black woman, health, and well-being in Nova 
Scotia. Health Care for Women International, 38(4), 379-393. https://doi.org/10.1 $\underline{080 / 07399332.2017 .1290099}$

Frank, B. (2010). Miracles could happen here: An external review of Cole Harbor district high school. Education Canada, 42(3), 28-31. https://www.edcan.ca/wp-content/ uploads/EdCan-2002-v42-n3-Frank.pdf

Finlayson, M. (2015). Cultural sustainability of African Canadian heritage: Engaging students in learning, the past, the present and the future. Improving Schools, 18(2), 142-156. https://doi.org/10.1177/1365480215575350

Halifax Regional School Board (HRSB). (2003). Improving the success of African Nova Scotian students: Findings of the research pilot project. Halifax Regional School Board.

Hamilton-Hinch, B. (2016). Surviving the impact of the experience of racism on health and well-being: An exploration of women of African ancestry living in Nova Scotia [Unpublished doctoral dissertation]. Dalhousie University. https://dalspace. library.dal.ca/bitstream/handle/10222/73601/Hamilton-Hinch-Barbara-Ann-PhDINTE-December-2015.pdf? sequence $=1 \&$ isAllowed $=\mathrm{y}$

Hamilton-Hinch, B., Harkins, M. J., \& Seselja, D. (2017). Implementing culturally sensitive pedagogies. Proceedings of the Atlantic Universities' Teaching Showcase, 21, 99-114. https://ojs.library.dal.ca/auts/article/view/8476

Irvine, J. J. (1990). Black students and school failure: Policies, practices, and prescriptions. Greenwood Press.

James, C. (2012). Students "at risk": Stereotypes and the schooling of Black boys. Urban Education, 47(2), 464-494.

James, C. (2013). Equity, social justice, and the inclusive classroom (research for teachers). Magazine of the Elementary Teacher's Federation of Ontario: EFTO Voice. http://etfovoice.ca/node/579

James, C., Este, D., Bernard, W. T., Benjamin, A., Lloyd, B., \& Turner, T. (2010). Race $\&$ well-being the lives, hopes and activism of African Canadians. Fernwood Publishing. 
Ladson-Billings, G. (1994). The dreamkeepers: Successful teachers of African American children. Wiley \& Sons.

Lee, E., \& Marshall, C. ( 2009). Reality check: A review of key program areas in the $B L A C$ report for their effectiveness in enhancing the educational opportunities and achievement of African Nova Scotian learners. Enidlee Consultants Inc.

Livingstone, A. M., Celemencki, J., Calixte, M. (2014). Youth participatory action research and school improvement: The missing voices of Black youth in Montreal. Canadian Journal of Education, 37(1) 283-307. https://www.jstor.org/ stable/10.2307/canajeducrevucan.37.1.283

Logan, W., L. \& Scarborough, J. L. (2008). Connection through clubs: Collaboration and coordination of a schoolwide program. Professional School Counseling, 12(2), 157-161. doi.org/10.1177/2156759X0801200212

McGibbon, E. A., \& Etowa, J. (2009). Anti-racist health care practice. Canadian Scholars' Press.

Miles M. B., \& Huberman, A. M. (1994). Qualitative data analysis: An expanded sourcebook. Sage.

Morgan, D. L. (1996). Focus groups. Annual Review of Sociology, 22, 129-152.

Morgan, D. L. (1997). Focus groups as qualitative research. Sage

Neergaard, M. A., Olesen F., Andersen R. S., \& Sondergaard J. (2009). Qualitative description - the poor cousin of health research? BMC Medical Research Methodology, 9(1), 52.

Neuman, W. L., \& Robson, K. (2007). Basics of social research: Qualitative and quantitative approaches. Pearson Canada.

Nova Scotia Department of Education and Early Childhood Development. (2016). Individual program plan review. Government of Nova Scotia.

Nova Scotia Human Rights Commission. (2017, September 25). Serious concerns raised by $U N$ regarding systemic discrimination faced by African Nova Scotian. https://humanrights.novascotia.ca/news-events/news/2017/ serious-concerns-raised-un-regarding-systemic-discrimination-faced-african 
Palinkas, L. A., Horwitz, S. M., Green, C. A., Wisdom, J. P., Duan, N., \& Hoagwood, K. (2015). Purposeful sampling for qualitative data collection and analysis in mixed method implementation research. Administration and Policy in Mental Health, $42(5), 533-544$.

Pachai, B. (2007). The Nova Scotia Black experience through the centuries. Nimbus.

Reinharz, S. (1992). Feminist methods in social research. Oxford University Press.

Ristock, J., \& Pennell, J. (1996). Community research as empowerment: Feminist links, postmodern interruptions. Oxford University Press.

Rummens, J., \& Dei, G. (2010). Including the excluded: De-marginalizing immigrant/ refugee \& racialized students. Education Canada Network, 50(5). https://www. edcan.ca/articles/including-the-excluded-de-marginalizing-immigrantrefugee-andracialized-students/

Sandelowski, M. (2000). Whatever happened to qualitative description? Research in Nursing Health, 23(4), 334-340.

Smith, A., Schneider, B., \& Ruck, M. (2005). “Thinking about makin' it”: Black Canadian students' beliefs regarding education and academic achievement. Journal of Youth and Adolescence, 34(4), 347-359.

Sue, D. W., Capodilupo, C. M., \& Holder, A. M. B. (2009). Racial microagresssions in the life experience of Black Americans. Professional Psychology: Research and Practice, 39(3), 329-336.

Thiessen, V. (2009). Identity, equity, and performance: Mathematics and reading literacy in Nova Scotia public schools. Nova Scotia Department of Education. http://www. $\underline{\text { rdc-cdr.ca/identity-equity-and-performance-mathematics-and-reading-literacy- }}$ nova-scotia-public-schools

United Nations. (2014). Recognition adopted by the General Assembly on 18 November 2014: Programme of activities for the implementation of the International Decade for People of African Descent. https://undocs.org/en/A/RES/69/16

United Nations Human Rights Council. (2017). Report of the working group of experts on people of African Descent on its mission to Canada. United Nations. https:// digitallibrary.un.org/record/1304262? $1 \mathrm{n}=\mathrm{en}$ 
Varma-Joshi, M., Baker, C. J., \& Tanaka, C. (2004). Names will never hurt me? Harvard Educational Review, 74(2), 175-208.

Waldron, I. (2018). Re-thinking waste: Mapping racial geographies of violence on the colonial landscape. Environmental Sociology, 4(1), 36-53.

Walker, J. W. St. G. (1992). The Black Loyalists: The search for a promised land in Nova Scotia and Sierra Leone, 1783-1870. University of Toronto Press. https:// utorontopress.com/ca/the-black-loyalists-2

Winks, R. (1997). The Blacks in Canada: A history. McGill-Queen's University Press.

Yull, D., Blitz, L., Thompson, T., \& Murray, C. (2014). Can we talk? Using communitybased participatory action research to build family and school partnerships with families of color. School Community Journal, 24(2), 9-31.

Wiersma, W., \& Jurs, S. G. (2009). Research methods in education: An introduction (8th ed). Allyn \& Bacon. 